\title{
Resenha do livro: \\ GONDRA, José Gonçalves; SCHUELER, Alessandra. Educação, poder e sociedade no Império Brasileiro. Sao Paulo: Cortez, 2008.
}

\author{
Resenha de: \\ Surya Aaronovich Pombo de Barros \\ Universidade Federal da Paraíba/UFPB
}

Realizar uma "nova síntese" da história da educação brasileira durante o Império, fugindo de teses generalistas e apresentando pesquisas realizadas recentemente é o objetivo do livro Educação, poder e sociedade no império brasileiro, de José G. Gondra e Alessandra Schueler, lançado em 2008.

Os autores, pesquisadores e autores na área, possuem larga experiência; ele, professor da UERJ e ela, da UFF. Essa inserção, aliada ao estado atual da História da Educação no Brasil, justificam o tipo de produção realizada. Retomando o compêndio, comum no início da história da educação, mas apresentando o acúmulo de produção de conhecimento observado neste campo, eles realizam uma síntese da educação brasileira no século XIX.

$\mathrm{Na}$ Introdução, Gondra e Schueler delimitam os três pontos que entendem como centrais: periodização escolhida, explicitação do que entendem por educação e, por fim, debatem a própria idéia de Brasil. Embora em algum momento afirmem que farão isso, não deixam explícito o posicionamento teórico seguido, o que talvez fosse desejável numa obra direcionada a graduandos.

Retomando a cronologia consolidada na historiografia brasileira - Colônia, Império e República -, os autores concordam com as pesquisas que "têm demonstrado que o emprego desses marcos e a unidade que a adoção deles sugere são insuficientes para explicar a complexidade da ação social nos períodos assim definidos”. Ainda assim, os utilizam, mas destacam "trabalhar com essa periodização, sensíveis a perceber que a experiência educativa não se encontra plenamente determinada pela forma administrativa no que foi uma 'América portuguesa' que, de modo tenso, desde então, vem construindo a forma de um Estado independente" (p. 10).

Os autores dividem a educação brasileira no Império sob dois critérios: "formas institucionalizadas" - diversas forças educativas e iniciativas específicas para a abertura de escolas no vasto território que se pretende unificar como Brasil e, também, iniciativas criadas, mantidas e expandidas pelo Estado e outras instituições como Igrejas e iniciativas privadas; e "formas não institucionalizadas", como a ação invisível processada em espaços privados, que "ajuda a compreender como o homem vem sendo educado e como temos compreendido a possibilidade de educar o homem" (p. 10).

Uma vez que, para os autores, "a educação ingressara definitivamente na agenda das preocupações sociais, sendo objeto de soluções variadas para atender a uma população heterogênea que precisava ser minimamente educada e disciplinada" (p. 11), contribuindo para a construção da idéia de Brasil, eles a colocam entre as diversas ações empreendidas no período com a incumbência de construir a nação brasileira. Seu objetivo é "ressaltar que a própria idéia de Brasil vem sendo construída ao longo do tempo e nem sempre foi a mesma, para o que concorre o lugar reservado à educação no âmbito deste audacioso 
projeto. Inversamente, cabe discutir o que a educação vem efetivamente fazendo para 'inventar'o próprio Brasil" (p. 13).

Fugindo da visão que já foi recorrente nos manuais de História da Educação Brasileira sobre o Oitocentos, que considerava o período como símbolo do atraso, do vazio, Gondra e Schueler, utilizando pesquisas acadêmicas recentes, principalmente da História e da História da Educação, e núcleo documental diversificado, se propõem a fazer uma síntese não definitiva que poderá ajudar a "estudantes de graduação e estudiosos e interessados na reflexão acerca da educação de modo geral" (p. 14) a conhecer - e ultrapassar - "o estágio atual da ciência disponível sobre a educação no surpreendente, aberto e inapreensível século XIX" (p. 17).

No primeiro capítulo, Formas do Brasil e Formas da Educação, os autores relacionam a constituição da educação escolar durante o início do século XIX com os projetos de nação e a formação do Estado brasileiro, destacando os trabalhos que demonstram a pluralidade das formas e processos educativos presentes ao longo da história da educação brasileira. Segundo eles,

estes novos estudos, em sua diversidade teórico-metodológica, se caracterizam pelo abandono de explicações generalizantes sobre os supostos insucessos da história educacional brasileira, na medida em que enfocam a heterogeneidade das formas de educação e de apropriação dos modelos educacionais, enfatizando a pluralidade das possibilidades históricas e usos diversos que os agentes fazem das instituições educativas, escolares e não-escolares, remodelando e reconstruindo os espaços, os saberes e os tempos sociais (p. 19).

Tal pluralidade pode ser encontrada já no século XVIII, motivo pelo qual os autores remontam ao período, discutindo como as Reformas Pombalinas modificaram o panorama da instrução no Império português, uma vez que a expulsão dos jesuítas trouxe a necessidade de reorganização do ensino. Gondra e Schueler debatem essas mudanças à luz do despotismo ilustrado, representado pelo Marquês de Pombal, que pretendia "retirar Portugal do atraso e reabilitar o 'poderosos império luso-brasileiro" (p. 22). Assim, o livro vai apresetando quase cronologicamente as mudanças pelas quais passa o Império português e as consequências dessas para a educação brasileira: transferência da Família Real, Período Joanino, Independência, Revoltas Regenciais: processos que evidenciam a necessidade de "construção" do Estado e do povo brasileiro.

Utilizando pesquisas consagradas da História do Brasil e da História da Educação, assim como consulta a fontes primárias, Gondra e Schueler destacam o processo de escolarização na sociedade a partir da ação do que chamam de "mecanismos articulados" na "invenção do brasil": legislação escolar e política educacional, constituição de aparato técnico e burocrático e controle dos serviços educacionais e produção de dados estatísticos por parte do Estado. Após apresentar e discutir tais mecanismos, os autores ressaltam que embora o Estado tenha um papel fundamental nos debates, perceber as demandas populares também é fundamental para compreender o período: "a difusão de saberes elementares, da cultura escrita e as disputas pelo acesso às escolas permaneceriam latentes em uma sociedade marcada pela diversidade de culturas regionais e locais" (p. 39).

Esse é o mote para o segundo capítulo, As Forças Educativas: quem pensava e fazia a educação no Império. Eles dividem tais iniciativas (tomadas por Estado, Igreja e 
Sociedade Civil) em poder público (leis e ações religiosas) e redes de sociabilidade (homens ilutrados). Começam tratando do poder público: "nosso recorte privilegia o Estado-nação, dada a engrenagem extensa e complexa estabelecida por essa forma de representar, organizar e fazer funcionar a sociedade" (p. 41). Intercalando apresentação de fatos históricos com análise de como eles contribuíram para a organização da instrução escolar, Gondra e Schueler discutem as três leis gerais criadas na primeira metade do século XIX: Constituição de 1824, Lei de 1827 e Ato Adicional de 1834. Eles defendem que o modo como tal legislação foi discutida e aprovada ajuda entender a construção do Brasil e do povo brasileiro e a pensar no monopólio do Estado em relação à matéria educacional. As leis específicas para a instrução deram a forma das escolas de primeiras letras, definindo quem seriam os professores, tipos de alunos desejáveis (embora houvesse a intenção declarada de "derramar a instrução sobre toda a população"), e método oficial a ser utilizado, assim como o escopo de atuação das províncias (periferia) e do poder central (centro), conforme a opção explicativa dos autores.

Gondra e Schueler, ainda no mesmo capítulo, apresentam a ação religiosa como uma parte da atuação do Estado, que contou com a articulação com a Igreja Católica para dirrimir as disputas internas. Eles destacam a importância não apenas da obrigatoriedade do ensino religioso (católico) nas escolas ccmo, também, para "as iniciativas formais e não formais desenvolvidas por vários grupos religiosos no sentido de preservar suas crenças e poderes, o que vale não só para católicos e suas diferentes ordens, mas também para religiões protestantes, espíritas, afro-brasileiras, indígenas, orientais e do mundo árabe" (p. 59). Assim, reforçam o caráter de "nova síntese" do livro, ao considerar não apenas o usualmente registrado em obras de referência, mas de utilizar as pesquisas mais recentes da área: experiências de diversas ordens católicas, protestantes, a importância das religiões africanas, indígenas e de outras religiões também presentes no Brasil (como judeus e árabes) são inseridos no debate sobre as ações religiosas referentes à educação.

Finalizando o capítulo, Gondra e Schueler apresentam pesquisas sobre iniciativas educacionais oriundas da sociedade que chamam de "civil", mostrando que a educação durante o Império não foi matéria unicamente da ação estatal. São grupos e associações, academias e grêmios, que também colaboraram para dar forma à instrução escolar ao longo do Império. Eles discutem a existência de espaços de sociabiliades formais (associações estabelecidas e institucionalizadas como confrarias, irmandades religiosas, sociedades profissionais) e informais (relações familires e sociais, festas, espaços públicos), algumas ações, idéias e personalidades à frente das iniciativas, destacando a sua importância na constituição da educação brasileira.

O terceiro capítulo do livro, As formas educativas, trata das diferentes modalidades de instituições de instrução formal existentes no século XIX: escolas elementares, internatos e asilos, colégios e liceus e faculdades e academias superiores. Os autores apresentam dados, números, exemplos, retirados de fontes primárias como relatórios e leis e de fontes secundárias (livros e manuais), assim como de pesquisas sobre diferentes províncias brasileiras realizadas recentemente. Eles abarcam diferentes questões que envolviam a educação, como alcances da escola, relação da população com a instrução formal, formação e salário de professores, criação da rede de inspeção escolar, existência de tipos de alunos "especiais" (cegos, surdos-mudos, pobres, meninas). Apresentam, também, diferentes visões sobre a importância e necessidade da educação escolar no XIX, formação para o trabalho, as diferentes instituições para diferentes "classes" da população, concluindo com a apresentação dos debates sobre a formação superior e as instituições existentes. 
Em Sujeitos da Ação Educativa, Gondra e Schueler apresentam a existência, atuação e sentido de ser "Professores, Meninas e mulheres, Negros, Índios e Crianças" na educação brasileira ao longo do século XIX. Nesse capítulo, que ocupa quase metade das páginas do livro, os autores incorporam as pesquisas mais recentes na historiografia da educação brasileira, desconstruindo ideias que acompanharam textos e pesquisas durante décadas. Com a proposta explícita de atualizar tais discussões, os autores modernizam o "manual".

Deste modo remontam ao início da colonização, discutindo o "ser professor no Império Português". Destacam o papel da Companhia de Jesus na atuação docente, mas apresentam a ação de outras ordens religiosas. Retomam a discussão sobre diferentes formas e forças educativas, que "conformaram outros modos e agentes do aprender e do ensinar" (p. 158), defendendo que não apenas a Igreja formava professores. Assim, acompanham as discussões e iniciativas sobre a contratação e formação de professores, os processos e modelos de profissionalização docente, e as exigências impostas aos postulantes a esse ofício. A seguir, os autores debatem a presença feminina na instrução imperial, destacando a emergência do tema nas últimas décadas. Eles mencionam a mudança no olhar de pesquisadores da história da educação, que "têm apontado para a multiplicidade de experiências das meninas e mulheres de diversos grupos étnicos e sociais em práticas e processos de educação formais e informais [...]” (p. 201).

Seguindo o intuito de incorporar "grupos que, até pouco tempo, nao tinham assento na história da educação ou eram considerados apenas sob a perspectiva da exclusão, do silêncio, da subalternidade ou da anomia social" (p. 222), Gondra e Schueler debatem a relação entre negros e educação no século XIX, discutindo a historiografia da educação, experiências experimentadas por indivíduos e grupos negros escravos e livres, o sentido da instrução formal para tais sujeitos e sua presença na escola imperial. Eles concluem: "a História das relações entre os negros e a educação [...] permanece constituindo um dos grandes desafios" (p. 255). Movimento semelhante é feito em relação a outro grupo excluído das pesquisas: os indígenas. Eles apresentam as visões sobre a instrução que deveria (ou não) ser oferecida aos índios, a política indigenista imperial, alertando que "não é menos relevante o silenciamento que a História da Educação e o ensino de História vêm impondo à atuação dos homens, mulheres e crianças pertencentes aos mais varios grupos indígenas como sujeitos históricos" (p. 266). Assim, ultrapassam o período Imperial, destacando movimentos e experiências em relação à educação indígena, chegando aos dias atuais.

Finalmente, a obra inclui, também uma última categoria: crianças. Utilizam referências clássicas da história da infância, obras do período imperial, assim como pesquisas atuais, perpassando a discussão acerca da infância e sua incorporação nos debates educacionais no século XIX, alcançando os debates sobre as políticas educacionais para a infância brasileira no século XXI. Eles finalizam o capítulo conclamando "ao desafio de continuar pensando a respeito da necessidade da infância e dos atributos empregados para defini-la, e também refletir permanentemente a respeito da escola, de qual escola, para que tipo de sujeito e de que idade" (p. 287).

No capítulo final, Desafios para a História da Educação, José Gondra e Alessandra Schueler retomam desafios e questões enfrentados na escrita do livro: Educação, Poder, Sociedade e Império, analisados a partir de uma perspectiva relacional, foram aqui compreendidos como fenômenos que resultam da complexidade e da plurarilidade dos processos históricos, da ação e das lutras entre formas, forças, sujeitos e práticas sociais diversos. Buscando produzir uma síntese, ainda que provisória e 
incompleta, da educação brasileira no período do Império brasileiro, "nossa abordagem se distancia de algumas reflexões relativas ao século XIX, segundo as quais a educação oitocentista, via de regra, se encontra representada sob o signo do vazio, do atraso, das trevas ou das sombras" (p. 293).

Através da apresentação de gráficos, pequenos resumos ao longo do texto, citações de fontes primárias, utilização de pesquisas já consagradas e outras recentes das áreas de história e história da educação, assim como indicação de sites, livros de referência e bibliografias temáticas, os autores, generosamente, apresentam um trabalho que pode contribuir para uma melhor formação de alunos de graduação, modificar visões consolidadas (e ultrapassadas) sobre a educação brasileira no Império e popularizar a história da educação. 